\title{
Lung mass and neurogenic hyperventilation as a presentation of disseminated tuberculosis
}

Deena Yousif ${ }^{1}$, Sindhu Mohandas ${ }^{1}$, Sally Ward ${ }^{2}$, and Ronen Zipkin ${ }^{1}$

${ }^{1}$ Children's Hospital of Los Angeles

${ }^{2}$ Children's Hospital Los Angeles

March 6, 2021

\begin{abstract}
Disseminated tuberculosis (TB) in the pediatric population is relatively rare in the United States with variable nonspecific presentations. In this letter we discuss the case of 2-year-old child with a lung mass and central neurogenic hyperventilation with primary respiratory alkalosis as a rare pediatric presentation of disseminated tuberculosis with TB meningitis and pulmonary tuberculosis.
\end{abstract}

\section{Hosted file}

Letter to the Editor edited.pdf available at https://authorea.com/users/399847/articles/ 512258-lung-mass-and-neurogenic-hyperventilation-as-a-presentation-of-disseminatedtuberculosis

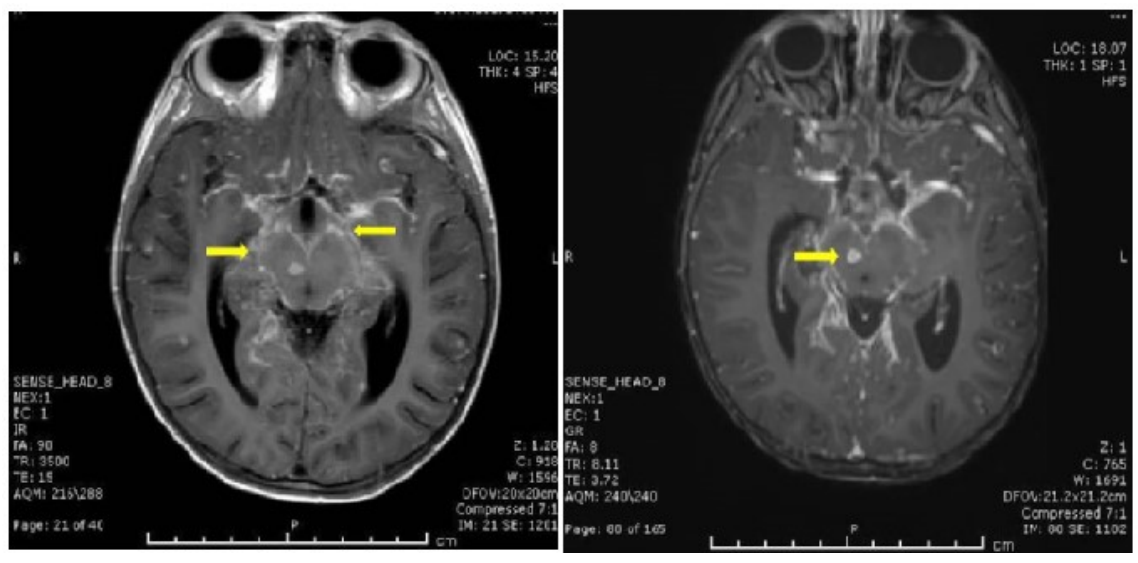

